\title{
Key Role of Complement Activation and Platelet- Activating Factor in Exudate Formation in Zymosan-Induced Rat Pleurisy
}

\author{
Yohsuke Imai, Masahiko Hayashi and Sachiko Oh-ishi* \\ Department of Pharmacology, School of Pharmaceutical Sciences, Kitasato University. \\ 5-9-1 Shirokane, Minato-ku, Tokyo 108, Japan \\ Received May 21, 1991 Accepted July 8, 1991
}

\begin{abstract}
Involvement of complement and platelet-activating factor (PAF) in zymosan-induced rat pleurisy was examined. Only a very low level of complement remained in the exudate at $1-5 \mathrm{hr}$ after zymosan injection, indicating that complement activation had occurred during this period in the pleural cavity. When rats were injected with cobra venom factor (CVF) $24 \mathrm{hr}$ prior to the zymosan injection to deplete complement, the exudate volumes at 0.5 and $5 \mathrm{hr}$ after zymosan injection were significantly reduced. Furthermore, combined treatment with CVF and CV-6209, an antagonist of PAF, also significantly suppressed the exudation but to no further extent than the suppression by CVF alone, suggesting that the level of complement depletion achieved was sufficient to halt PAF synthesis/release. To see if complement activation is involved in PAF production, we examined the PAF production by resident leukocytes in response to zymosan in vitro. When pleural leukocytes were stimulated with zymosan in the presence of rat serum, PAF-like activity both in the medium and in the cellular fraction increased. If the serum was heat inactivated, no PAF-like activity was detected. These results suggest that initial activation of the complement system may occur in the pleural cavity by zymosan and that the activated complement may then stimulate the production of PAF, which in turn elicits the exudate.
\end{abstract}

Rat pleurisy induced by intrapleural injection of zymosan has been reported previously $(1,2)$. In a previous paper, we demonstrated that histamine, serotonin, and pletelet-activating factor (PAF) were mediators acting on the exudation of the zymosan-induced pleurisy at $0.5 \mathrm{hr}$. We also reported that PAF may be involved in the zymosan-induced pleurisy at $5 \mathrm{hr}$ and $16 \mathrm{hr}$ in addition to its participation at the stage of $0.5 \mathrm{hr}$, based on data obtained by the use of a PAF-antagonist, CV-6209, and measurement of PAF in the exudate (1).
In this paper, we examined if the complement system may be involved in this particular pleurisy, and if complement activation may cause the release of histamine or PAF from resident cells in the pleural cavity, since zymosan is known to activate the alternative pathway of complement (3). We examined the effect of depletion of the complement system by the use of cobra venom factor (CVF) on the zymosan-induced pleurisy, and we also measured the complement titer in the exudate.

\footnotetext{
* To whom correspondence should be addressed.
} 


\section{MATERIALS AND METHODS}

\section{Materials}

1-1)-Hexadecyl-2-0-acetyl-sn-glycero-3-phosphocholine ( $\mathrm{C}_{16}$-PAF) (Bachem Feinchemikalien, Bubendorf, Switzerland) was a gift from Funakoshi Pharmaceut. Co., Tokyo. CV-6209 (2-[N-acety]-N-(2-methoxy-3-octadecyl-carbamoyloxypropoxycarbonyl)aminomethyl]-1-ethylpyridinium chloride) was kindly supplied by Takeda Chemical Industries, Ltd. (Osaka, Japan). Zymosan A (from $S$. cerevisiae, Sigma Chemical Co., St. Louis, MO), cobra venom factor (from Naja naja kaouthia, Sigma), $\left[{ }^{3} \mathrm{H}\right] \mathrm{C}_{16}$-PAF (1-0-[ $\left.{ }^{3} \mathrm{H}\right]$ hexadecyl-2-0)-acetyl-snglycero-3-phosphocholine, $1483.7 \mathrm{MBq} / \mathrm{mmol}$, New England Nuclear) were purchased. Sheep red blood cells (SRBC) and rabbit anti-sheep red blood cells (hemolysin) were obtained from Nihon Bio-Material Center, Tokyo. Anti rat $\mathrm{C} 3$ rabbit serum was purchased from Bethyl Lab. Inc., Montgomery, TX.

\section{Animals}

Eight-week old male Sprague-Dawley (SD) rats (Japan SLC, Inc., Hamamatsu, Japan) were used for induction of pleurisy and collection of resident pleural leukocytes. Male Brown Norway Kitasato (B/N-Ki, normal) and Brown Norway Katholiek (B/N-Ka, HMW- and LMW-kininogen-deficient) strain rats were bred and kept in the animal laboratory of Kitasato University as previously reported (4). Female Japanese white rabbits (2$3 \mathrm{~kg}$, Doken, Ibaragi, Japan) were used as the source of washed platelets.

\section{Induction of rat pleurisy and pretreatments}

Male $\mathrm{SD}$ rats or $\mathrm{B} / \mathrm{N}$ rats were intrapleurally injected with $0.1 \mathrm{ml}$ of $2 \%$ zymosan suspension in saline under light ether anaesthesia and sacrificed by exsanguination at the indicated time. For use, the above zymosan particles were washed with saline for $3 \mathrm{hr}$ and autoclaved. Then, the washed zymosan was suspended in sterilized physiological saline to 20 $\mathrm{mg} / \mathrm{ml}$. CV-6209 was dissolved in sterilized physiological saline at the dose of $1 \mathrm{mg} / \mathrm{ml}$ and intravenously injected. CVF $(7.5 \mu \mathrm{g} / 100 \mathrm{~g}$ body weight $/ 100 \mu \mathrm{l}$ ) was administered intravenously $24 \mathrm{hr}$ before the injection of zymosan. Measurement of exudation rate and total leukocyte count were performed as previously reported (5). The pleural exudates were collected and separated by centrifugation into the supernatant and cell pellet. The serum and supernatant of the exudate were used to test complement fixation, as described below.

\section{Measurement of hemolytic activity of comple-} ment

The hemolytic activity of complement (CH50) was measured by the method of Mayer and Kabat (6). In brief, SRBC sensitized with hemolysin were added to samples of scrially diluted serum or to those of the exudate of zymosan pleurisy. After incubation for $60 \mathrm{~min}$ at $37^{\circ} \mathrm{C}$, the samples were centrifuged to remove unlysed cells, and the clear supernatant fluid was then examined for absorption at $541 \mathrm{~nm}$. Total protein concentrations of the serum and exudate were measured by the method of Lowry et al. (7), and the activity was expressed as $\mathrm{CH} 50$ (unit per $\mathrm{mg}$ protein) (6).

Isolation of resident pleural leukocytes and stimulation with zymosan

Resident pleural leukocytes were collected from normal SD rats as previously reported (8). Washed resident pleural leukocytes were suspended in Hanks' balanced salt solution (HBSS) containing $\mathrm{Ca}^{2+}$ and $\mathrm{Mg}^{2+}$ and adjusted to $1 \times 10^{7} \mathrm{cells} / 0.9 \mathrm{ml}$. Aftcr preincubation for $10 \mathrm{~min}$ at $37^{\circ} \mathrm{C}$, the cells were then incubated with $0.1 \mathrm{ml}$ of zymosan suspension for the indicated times. The reaction was terminated by immediate cooling at $4^{\circ} \mathrm{C}$ and centrifugation for $1,600 \times g$ for $5 \mathrm{~min}$ at $4^{\circ} \mathrm{C}$. Separated supernatant and cell pellet were used to extract PAF activity for measurement, as indicated below.

\section{PAF extraction and assay}

PAF activity in the samples from the cells 
stimulated by zymosan was cxtracted and purified as described previously (8). Briefly, PAF was extracted by the method of Bligh and Dyer (9), and samples were cleaned up by passage through a Sep-Pak silica cartridge (Waters, Milford MA). PAF was scparated from other choline-containing phospholipids by HPLC, which was performed with a Toso model 8010 HPLC system fitted with a $\mu$-bondasphere silica column (Waters, $3.5 \times 150$ $\mathrm{mm}$ ) that was connected to a UV detector set at $206 \mathrm{~nm}$. The fractions corresponding to the retention time of authentic $\mathrm{C}_{16}-\mathrm{PAF}$ were eluted with isopropanol: hexane: water (110: $100: 20, \mathrm{v} / \mathrm{v} / \mathrm{v}$ ) at a flow rate of $0.5 \mathrm{ml} / \mathrm{min}$, pooled and evaporated to dryness under reduced pressure. The residue was resuspended in Tyrode's solution containing $0.25 \% \mathrm{BSA}$ and $1.3 \mathrm{mM} \mathrm{Ca}^{2-}$ and used for determination of PAF content by the method of washed platelet aggregation. The amount of PAF was calculated from the standard curve of authen- tic $\mathrm{C}_{16}-\mathrm{PAF}$ and corrected for the percent recovery obtained by the extraction procedure.

\section{Statistics}

Statistical evaluation was performed by Student's $t$-test. Differences with $\mathrm{P}<0.05$ and $\mathrm{P}$ $<0.01$ were considered significant .

\section{RESULTS}

Effect of pretreatment with CVF on the zymosan-induced rat pleurisy

As shown in Fig. 1, pretreatment of rats with CVF significantly reduced both exudate volume and exudation rate of zymosan pleurisy at $0.5 \mathrm{hr}$ and $5 \mathrm{hr}$ and leukocyte number at $5 \mathrm{hr}$. Depletion of the complement activity by such pretreatment with CVF was confirmed, since the complement titer of the serum was markedly reduced to almost the limit of detection $24 \mathrm{hr}$ after the intravenous injection of CVF as shown at the right side in

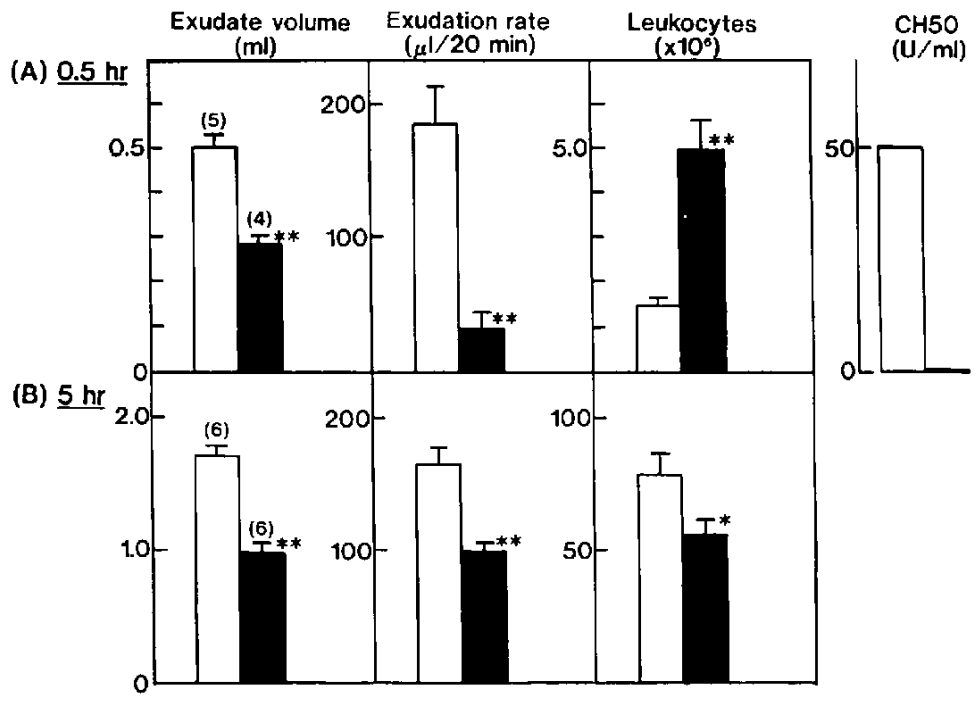

Fig. 1. Effect of cobra venom factor (CVF) on rat pleurisy induced by zymosan at $0.5 \mathrm{hr}(\mathrm{A})$ and $5 \mathrm{hr}$ (B). CVF $(7.5 \mu \mathrm{g} / 100 \mathrm{~g}$ body weight $/ 100 \mu 1)$ was administered into a tail vein $24 \mathrm{hr}$ prior to zymosan injection. As shown at the right, the serum complement level (CH50) was also measured $24 \mathrm{hr}$ after the injection of CVF. Numbers in parentheses show numbers of rats used, and vertical bars represent standard errors. ${ }^{*}$ and ** indicate values that are significantly different at $\mathrm{P}<0.05$ and $\mathrm{P}<0.01$, respectively, from those of the control. $П$ : control. $\mathbf{\square}$ : CVF. 
Fig. 1. As previously reported (1), CV-6209 suppressed exudation of zymosan pleurisy at $0.5 \mathrm{hr}$ and $5 \mathrm{hr}$. In the present experiments, we examined the effect of combined treatment with CVF and CV-6209 on zymosan pleurisy at $5 \mathrm{hr}$, as shown in Fig. 2. The exudate volume and the exudation rate at the 5 -hr stage were significantly suppressed by $\mathrm{CV}$ 6209. Although combined treatment with CVF and CV-6209 significantly suppressed the exudate accumulation and exudation rate, it caused no further suppression than that by CVF alone.

Time course changes of complement titers of serum and exudate in zymosan pleurisy

The exudate volume in the pleural cavity of rats with zymosan pleurisy increased up to 24 $\mathrm{hr}$, and the protein content in the exudate increased and reached a plateau at $8 \mathrm{hr}$, as shown in the upper panel of Fig. 3. Complement titer (CH50) of the serum did not change up to $24 \mathrm{hr}$ after injection of zymosan. However, that of the pleural fluids was significantly reduced at the period between $1 \mathrm{hr}$ and $5 \mathrm{hr}$ after the zymosan injection (lower panel of Fig. 3).
Induction of zymosan pleurisy in $B / N$ rats

Zymosan pleurisy was induced in the Brown Norway Kitasato $(\mathrm{B} / \mathrm{N}-\mathrm{Ki})$ and Brown Norway Katholick (B/N-Ka) rats. As cited in Table 1, zymosan induced pleurisy in both $\mathrm{B} / \mathrm{N}$ strains. There were no significant differences between the strains in the exudate volume, exudation rate, or leukocyte number of the pleurisy at $0.5 \mathrm{hr}, 5 \mathrm{hr}$ and $24 \mathrm{hr}$; and the values were similar to those for pleurisy induced in SD rats.

Production of PAF from rat resident pleural leukocytes in vitro

Resident pleural leukocytes from normal SD rats were stimulated with zymosan $(2 \mathrm{mg} / \mathrm{ml})$ in the presence of normal rat serum. The population of resident leukocytes was comprised of approximately $85 \%$ mononuclear leukocytes, $10 \%$ mast cell, and $5 \%$ others, with no detectable polymorphonuclear leukocytes. Intracellular and extracellular PAF activities increased following incubation, and their amounts increased linearly with the serum concentration in the medium up to $1 \%$, and then remained unchanged until $5 \%$, as shown in Fig. 4. When the leukocytes were stimu-

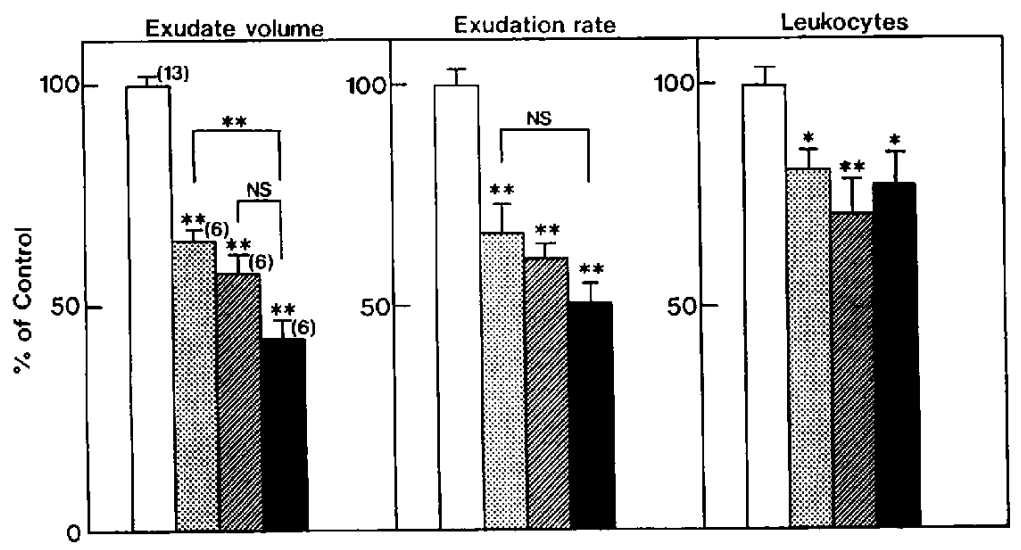

Fig. 2. Effect of combined treatment wich cobra venom factor (CVF) and/or CV-6209 on zymosan pleurisy at $5 \mathrm{hr}$. CVF $(7.5 \mu \mathrm{g} / 100 \mathrm{~g}$ body weight $/ 100 \mu \mathrm{l})$ was administered into a tail vein $24 \mathrm{hr}$ prior to zymosan injection. CV-6209 (1 mg/ kg) was injected by the same route $5 \mathrm{~min}$ prior to zymosan injection. Numbers in parentheses show numbers of rats used, and vertical bars represent standard errors. * and ** indicate values that are significantly different at $\mathrm{P}<0.05$ and $\mathrm{P}<0.01$. respectively, from those of the control or as indicated. NS: not significant. : control, $\$$ : CV-6209, 


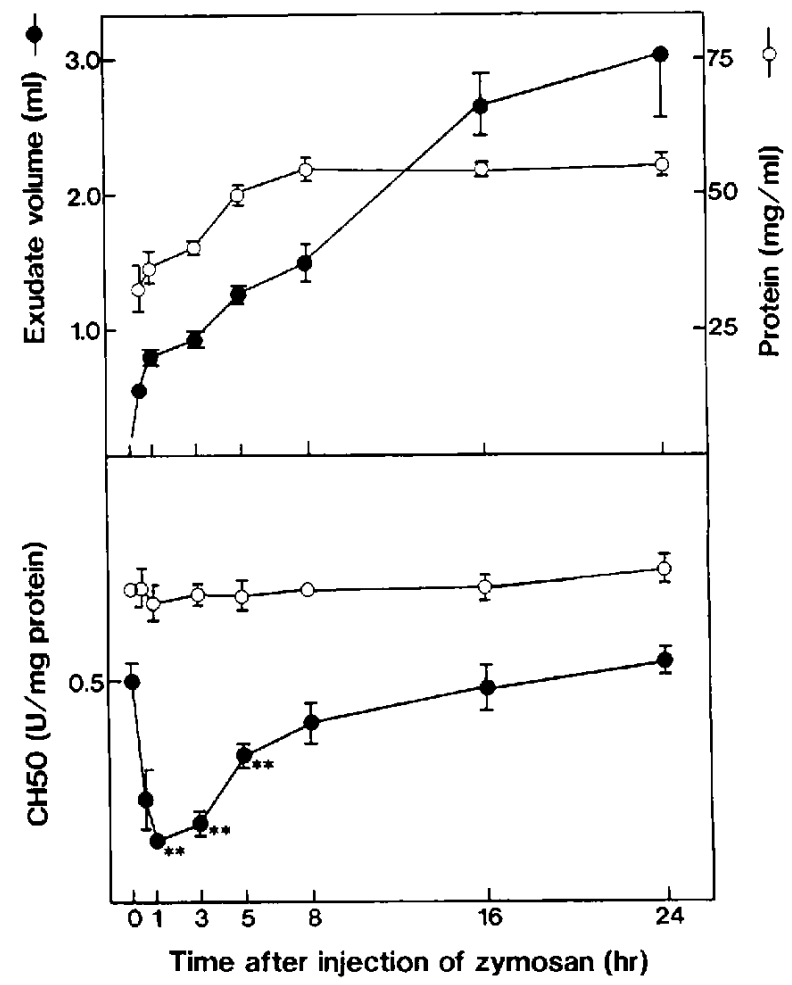

Fig. 3. Time course of exudate volume (O) and protein content (C) (upper panel) and of complement hemolytic activity $(\mathrm{CH} 50)$ in serum ( ) and exudate (O) (lower pancl) from rats with zymosan-induced pleurisy. Each point is the mean \pm S.E. of $4-6$ experiments. ${ }^{*}$ indicates values that are significantly differcnt at $\mathrm{P}<0.01$ from the corresponding ones of the control.

Table 1. Induction of zymosan pleurisy in Brown Norway rats

\begin{tabular}{|c|c|c|c|c|c|}
\hline Time & Animal & $\mathrm{n}$ & $\begin{array}{l}\text { Exudate volume } \\
\qquad(\mathrm{ml})\end{array}$ & $\begin{array}{l}\text { Exudation rate } \\
\qquad(\mu 1 / 20 \mathrm{~min})\end{array}$ & $\begin{array}{l}\text { I.eukocytes } \\
\left(\times 10^{\mathrm{o}}\right)\end{array}$ \\
\hline $0.5 \mathrm{hr}$ & $\begin{array}{l}\mathrm{B} / \mathrm{N}-\mathrm{Ki} \\
\mathrm{B} / \mathrm{N}-\mathrm{Ka}\end{array}$ & $\begin{array}{l}4 \\
4\end{array}$ & $\begin{array}{l}0.27 \pm 0.01 \\
0.31 \pm 0.03\end{array}$ & $\begin{array}{r}94.2 \pm 19.8 \\
130.3 \pm 13.2\end{array}$ & $\begin{array}{l}5.4 \pm 1.0 \\
6.7 \pm 0.9\end{array}$ \\
\hline $5 \mathrm{hr}$ & $\begin{array}{l}\mathrm{B} / \mathrm{N}-\mathrm{Ki} \\
\mathrm{B} / \mathrm{N}-\mathrm{Ka}\end{array}$ & $\begin{array}{l}8 \\
6\end{array}$ & $\begin{array}{l}1.80 \pm 0.04 \\
1.78 \pm 0.09\end{array}$ & $\begin{array}{l}168.6 \pm 16.3 \\
170.9 \pm 20.6\end{array}$ & $\begin{array}{l}140.6 \pm 13.4 \\
133.3 \pm 3.4\end{array}$ \\
\hline $24 \mathrm{hr}$ & $\begin{array}{l}\mathrm{B} / \mathrm{N}-\mathrm{Ki} \\
\mathrm{B} / \mathrm{N}-\mathrm{Ka}\end{array}$ & $\begin{array}{l}5 \\
7\end{array}$ & $\begin{array}{l}2.63 \pm 0.60 \\
2.46 \pm 0.28\end{array}$ & $\begin{array}{l}49.3 \pm 14.5 \\
54.3 \pm 9.8\end{array}$ & $\begin{array}{l}218.7 \pm 8.1 \\
229.8 \pm 18.7\end{array}$ \\
\hline
\end{tabular}

Rat pleurisy was induced by intrapleural injection of zymosan, and the animals were then sacrificed at $0.5 \mathrm{hr}, 5 \mathrm{hr}$, and $24 \mathrm{hr}$ thereafter. Brown Norway Kitasato rats (B/N-Ki: normal) and Brown Norway Katholiek rats (B/N-Ka: HMW-and LMW-kininogen deficient) were used. Values indicate means with standard error. 


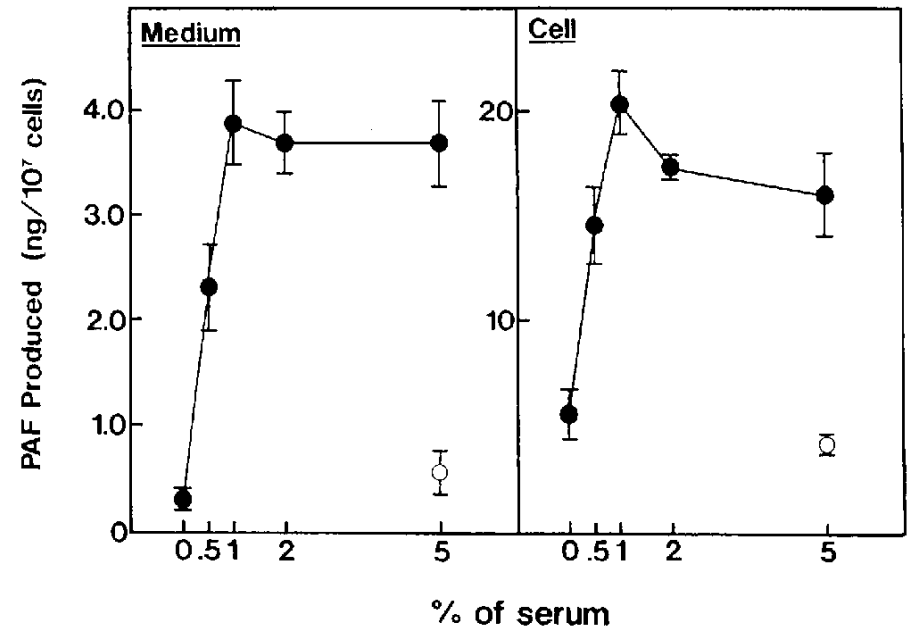

Fig. 4. Dose-response effect of serum on platelet-activating factor (PAF) production by resident pleural leukocytes stimulated by zymosan. Rat pleural resident leukocytes $\left(1 \times 10^{7}\right)$ were stimulated with $2 \mathrm{mg}$ of zymosan for $30 \mathrm{~min}$ at $37^{\circ} \mathrm{C}$. The open circle indicates the result when $5 \%$ serum heated at $56^{\circ} \mathrm{C}$ for 30 min was used. Each point is the mean $\pm \mathrm{S}$.E. of $4-8$ experiments.

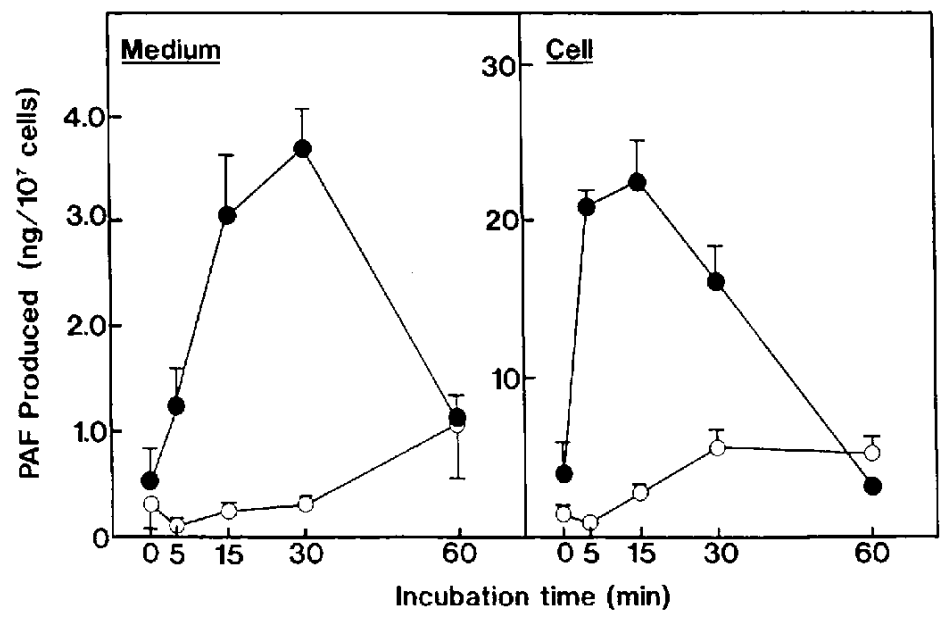

Fig. 5. Time course of platelet-activating factor (PAF) production by rat resident pleural leukocytes stimulated by zymosan in the presence $(O)$ or absence $(\bigcirc)$ of $5 \%$ serum. Rat resident pleural lcukocytes $(1 \times$ $10^{7}$ ) were stimulated with zymosan ( $2 \mathrm{mg}$ ). Each point is the mean $\pm \mathrm{S}$.E. of $4-8$ experiments.

lated with zymosan in medium containing $5 \%$ serum, that had been heated at $56^{\circ} \mathrm{C}$ for 30 min prior to use, enhancement of PAF synthesis was not observed (open circle in Fig. 4).

The time course of PAF synthesis in pleural leukocytes stimulated with zymosan in medium containing 5\% serum is shown in Fig. 5. Intracellular PAF immediately increased, reaching its peak $15 \mathrm{~min}$, and then declined. PAF activity in the medium increased gradually up to $30 \mathrm{~min}$ and then decreased. To evaluate cell toxicity, we estimated lactate dehydrogenase (LDH) release by the LDH-UVtest (Boehringer-Mannheim Co.). No significant difference in LDH release was observed between cells in the control incubation me- 
dium (without zymosan) and zymosan-treated pleural leukocytes up to 60 min (data not shown). When pleural cells were incubated with zymosan in the absence of serum, only a small amount of PAF was detected, and it was mostly retained in the cells (Fig. 5).

\section{DISCUSSION}

We previously reported that in zymosan-induced rat pleurisy, histamine and/or serotonin and PAF were involved in the 0.5 -hr exudation and that PAF was also a mediator of 5-hr exudation (1). The PAF-antagonist CV-6209 suppressed the exudation at $5 \mathrm{hr}$ only by $50 \%$. even when a sufficient dose of the antagonist was used. Therefore, we considered that complement might be another mediator at $5 \mathrm{hr}$.

Since zymosan is a well-known activator of the alternative pathway of the complement system (3), we measured the complement titer in the exudate during zymosan pleurisy (Fig. 3 ). Whereas complement activity, expressed as CH50, in the serum did not change throughout the pleurisy up to $24 \mathrm{hr}$, that in the exudate was markedly reduced at $1-5 \mathrm{hr}$ after zymosan injection and restored after $16 \mathrm{hr}$. This result clearly indicates that complement activation occurred locally in the pleural cavity. In support of this finding of complement activity in the pleural exudate, we noted that this extravascular fluid contained a protein level (Fig. 3) and composition similar to those of serum.

To further explore complement involvement, we examined the effect on the exudation process of in vivo depletion of complement by treatment of rats with CVF. CVF is known as a C3b-like protein and is used for depletion of the complement system $(10,11)$. Pretreatment of rats with CVF significantly suppressed exudation of the zymosan-induced pleurisy at 0.5 and $5 \mathrm{hr}$ (Fig. 1). As seen in Fig. 1, leukocyte number at $0.5 \mathrm{hr}$ in the group with CVF-treatment was significantly increased to the level of normal rats (about 5$10 \times 10^{6}$ resident cells). One possible explanation for this is that CVF might prevent adhe- sion or degradation of resident leukocytes. On the contrary, leukocyte number at $5 \mathrm{hr}$ in the CVF-treated group was significantly reduced. The effect could be considered to result from the following events: depletion of complement by CVF could reduce the production of chemotactic factors such as anaphylatoxins and PAF, which might result in the reduction of leukocyte migration into the pleural cavity. However, such chemotactic factors and their effect should be clarified in the future.

Under this circumstance, serum complement activity of the rats was almost undetectable. Earlier we reported that at the initial phase of zymosan pleurisy, i.e., at $0.5 \mathrm{hr}$, histamine and/or serotonin, and PAF could be responsible for induction of exudation, since antagonists of these mediators significantly suppressed the exudation process (1). Also, PAF was found to be involved at $5 \mathrm{hr}$ as well, while cyproheptadine at $5 \mathrm{hr}$ and indomethacin at both $0.5 \mathrm{hr}$ and $5 \mathrm{hr}$ did not have any effect (1). Therefore, focusing on the involvement of PAF, we undertook combined treatment of the rats with CVF and the PAF-antagonist CV-6209. The results showed that no further marked suppression of exudation was observed over the suppression achieved by CVF alone, suggesting that complement activation may be the initial event, leading to activation of successive PAF synthesis or histamine release, which in turn is responsible for the $50 \%$ drop in exudate volume.

In order to examine if activated complement induces PAF synthesis, in vitro incubation of resident leukocytes with zymosan was undertaken. As shown in Fig. 4, zymosan in the presence of normal rat serum induced an increase in PAF content in rat leukocytes, whereas no increase was seen with heat-inactivated serum or without serum. This result indicates that the presence of normal serum is necessary for the increase in PAF and strongly suggests involvement of serum enzymc systems, such as complement activation.

The kallikrein-kinin system may not be involved in the early stage of the zymosan-pleurisy, since as was shown in Table 1 , the 
$\mathrm{B} / \mathrm{N}-\mathrm{Ka}$ rats, which are a HMW-kininogendeficient strain (4), did not show any difference in exudate volume and exudation rate from the normal strain. In carrageenininduced pleurisy, the deficient strain showed significantly less accumulation of exudate (12).

In conclusion, the complement system is activated at the early stage of rat zymosan pleurisy, and the zymosan injected into the pleural cavity activates the complement system by contact with the interstitial fluid. This activated complement thus enhances PAF synthesis, and possibly that of other mediators, in the resident leukocytes. Since the exudate was reduced by only about half when complement and PAF were nullified, these components are not the only ones involved in exudate formation.

\section{Acknowledgment}

The authors are grateful to Mr. Hiroaki Naraba for his technical assistance.

\section{REFERENCES}

1 Imai, Y., Hayashi, M. and Oh-ishi, S.: Involvement of platelet-activating factor in zymosan-induced rat pleurisy. Lipids 26 (12) (1991) (in press)

2 Martins, M.A., Silva, P.M.R., Castro Faria Neto. H.C., Bozza, P.T., Dias, P.M.F.L., Lima, M.C.R., Cordeiro, R.S.B. and Vargaftig, B.B.: Pharmacological modulation of Paf-induced rat plcurisy and its rolc in inflammation by zymosan. Br. J. Pharmacol. 96, 363-371 (1989)

3 Pillemer, L., Blum, L.. Lepow, I.H., Ross, O.A.. Todd, E.W. and Wardlaw, A.C.: The properdin system and immunity: I. Demonstration and isolation of a new serum protein, properdin, and its role in immune phenomena. Science 20, 279-285 (1954)
4 Oh-ishi, S., Satoh, K., Hayashi, I., Yamazaki, K. and Nakono, T.: Differences in prekallikrein and high molecular weight kininogen levels in two strains of Brown Norway rat (Kitasato strain and Katholiek strain). Thromb. Res. 28, 143-147 (1982)

5 Kawamura, K. and Oh-ishi, S.: Rat pleurisy induced by kaolin or croton oil: Time course of fluid accumulation and white cell migration. Int. J. Tissue React. 7, $381-386$ (1985)

6 Mayer, M.M.: Complement and complement fixation. In Experimental Immunochemistry. 2nd edition, Edited by Kabat, E.A. and Mayer, M.M., p. 133-240, Charles C. Thomas, Springfield (1961)

7 Lowry, O.H., Rosebrough, N.J., Farr, A.L. and Randall, R.J.: Protein measurement with the Folin Phenol reagent. J. Biol. Chem. 193, 265-275 (1951)

8 Hayashi, M., Kimura, J., Yamaki, K., Suwabe, Y., Dozen. M., Imai, Y. and Oh-ishi, S.: Detection of platelet-activating factor in cxudates of rats with phorbol myristate acetate-induced pleurisy. Thromb. Res. 48, $299-310$ (1987)

9 Bligh, E.G. and Dyer, W.J.: Rapid mehod of total lipid extraction and purification. Can. J. Biochem. Physiol. 37, $811-817$ (1959)

10 Cochrane, C.G., Mueller-Eberhard, H.J. and Aikin, B.S.: Depletion of plasma complement in vivo by protein of cobra venom: its effect on various immunologic reactions. J. Immunol. 105 , $55-69$ (1970)

11 Alper, C.A. and Balavitch, D.: Cobra venom factor: Evidence for its being altered C3 (the third component of complement). Science 191, $1275-$ 1276 (1976)

12 Oh-ishi, S., Hayashi, I., Hayashi, M., Yamaki, K., Yamasu, A., Nakano, T., Utsunomiya, I. and Nagashima, Y.: Evidence for a role of the plasma kallikrein-kinin system in acute inflammation: reduced exudation during carrageenin- and kaolinpleurisies in kininogen-deficient rats. Agents Actions 18, 450-454 (1986) 